\title{
A mechanism for dust-induced destabilization of glacial climates
}

\author{
B. F. Farrell ${ }^{1}$ and D. S. Abbot ${ }^{2}$ \\ ${ }^{1}$ Department of Earth and Planetary Sciences, Harvard University, Cambridge, Massachusetts, USA \\ ${ }^{2}$ Department of Geophysical Sciences, University of Chicago, Chicago, Illinois, USA \\ Correspondence to: B. F. Farrell (farrell@seas.harvard.edu)
}

Received: 4 April 2012 - Published in Clim. Past Discuss.: 15 May 2012

Revised: 30 November 2012 - Accepted: 3 December 2012 - Published: 18 December 2012

\begin{abstract}
Abrupt transitions between cold/dry stadial and warm/wet interstadial states occurred during glacial periods in the absence of any known external forcing. The climate record preserved in polar glaciers, mountain glaciers, and widespread cave deposits reveals that these events were global in extent with temporal distribution implying an underlying memoryless process with millennial time scale. Here a theory is advanced implicating feedback between atmospheric dust and the hydrological cycle in producing these abrupt transitions. Calculations are performed using a radiative-convective model that includes the interaction of aerosols with radiation to reveal the mechanism of this dust/precipitation interaction feedback process and a Langevin equation is used to illustrate glacial climate destabilization by this mechanism. This theory explains the observed abrupt, bimodal, and memoryless nature of these transitions as well as their intrinsic connection with the hydrological cycle.
\end{abstract}

\section{Introduction}

A central problem in climate science is understanding abrupt climate change such as the Dansgaard-Oeschger (D-O) transitions during glacials. These abrupt transitions are global in extent and strongly influence the hydrological cycle. Their imprint on global precipitation can be seen in polar glacier records of ice accumulation (Steffensen et al., 2008; Alley et al., 1993), midlatitude glacier records (Thompson et al., 1989), widespread cave oxygen isotope records indicating major changes in monsoonal circulations (Wang et al., 2001; Fleitmann et al., 2003; Yuan et al., 2004; Dykoski et al., 2005), and oxygen isotope and methane data that are intimately tied to tropical precipitation (Chappellaz et al.,
1993). Rapid increase in methane during abrupt warming events implies tropical precipitation changed coincident with rapid changes in midlatitude Asian monsoon precipitation (Ruth et al., 2007) and Greenland ice accumulation rates (Mayewski et al., 1993).

Antarctic and Greenland ice core records indicate that in polar regions order-of-magnitude changes in atmospheric dust and aerosol loading were associated with changes in precipitation during abrupt climate transitions (Lambert et al., 2008; Fuhrer et al., 1999). The Greenland record shows that atmospheric dust covaried with precipitation on the time scale of a few years (Fuhrer et al., 1999; Steffensen et al., 2008). Although less resolved compared to the Greenland record, Antarctic ice cores also show large and rapid variations in dust accumulation synchronous with temperature change (Lambert et al., 2008). During glacials, equatorial Pacific dust flux covaries on orbital time scales with benthic $\delta^{18} \mathrm{O}$ derived global ice volume and also with Antarctic dust flux both at orbital and suborbital time scales (Winckler et al., 2008). Although evidence for this cold/dry/dusty covariation resolved at millennial timescale is primarily obtained from cores, indirect evidence for this association during cold intervals is widespread. This evidence includes extensive loess deposits (Sun et al., 2006) and reconstructions of a vast arid steppe ecology inhabited by the Pleistocene megafauna in areas characterized by paludal tundra during the Holocene (Guthrie, 2001). Increased atmospheric dust during stadials (Thompson et al., 1989; Lambert et al., 2008) is consistent with a reduction in the hydrological cycle while decreased dust during interstadials is consistent with return of pluvial conditions, due to both the influence of surface moisture on dust sources and the relation of atmospheric dust residence time to precipitation mediated scavenging by wet deposition (Yung et al., 1996). 
Abrupt climate change, such as the D-O transitions, occur on time scales rapid compared to orbital, ice albedo and $\mathrm{CO}_{2}$ variation, which precludes these factors as the proximal cause of the abrupt transition. The rapidity of these changes argues for a nonlinear climate switch mechanism (Clement and Peterson, 2008; Ditlevsen, 1999). Furthermore, the exponential waiting time distribution between the D-O abrupt climate transitions and the Poisson distribution of the abrupt change intervals implies that these transitions are produced by a memoryless underlying process (Ditlevsen, 2009), while the absence of either increased variance or increased autocorrelation on approach to the transitions implies that these transitions do not result from a bifurcation (Ditlevsen and Johnsen, 2010), but are rather noise induced transitions between stable climate equilibria.

Current theories of abrupt climate change involve nonlinear switches in the thermohaline circulation (THC) (Weaver et al., 1991), sea ice formation (Gildor and Tziperman, 2003), and storm track location (Farrell and Ioannou, 2003). The direct effect of these transition mechanisms is local to the North Atlantic region and teleconnections mediated through the ocean and atmosphere are invoked to produce the global climate changes seen in the proxy record (Seager and Battisti, 2007). Involvement of the North Atlantic THC in abrupt climate change events is clear in the sea core record (McManus et al., 2004) but the mechanism instigating these THC changes, which is thought to be related to the freshwater/salinity balance of the North Atlantic, has not been determined (Seager and Battisti, 2007). With these considerations as context we propose a mechanism for initiating the chain of events leading to abrupt climate transitions based on a dustinduced destabilization of the global hydrological cycle.

\section{The mechanism of dust destabilization}

Transitions between climate states that are bimodal, rapid, memoryless, and not associated with increased variance or increased temporal autocorrelation on approach to the transition point imply a stochastically induced transition between two stable states. The rapid simultaneous change in the hydrological cycle in both low and mid latitudes implies this transition is related to a global precipitation distribution change (Rohling et al., 2003). Moreover, this transition must involve strong enough positive feedbacks to produce and maintain two stable states, one dry/cold and one wet/warm.

An analogue of glacial abrupt climate change on Earth is seen on Mars where rapid transition between a clear and a dusty state occurs during Martian northern summer (Fernández, 1997). This analogy is apt in that the Earth's climate shares with that of Mars a vulnerable interaction among atmospheric dynamics, dust, and radiation; with the additional involvement of the hydrological cycle in the case of

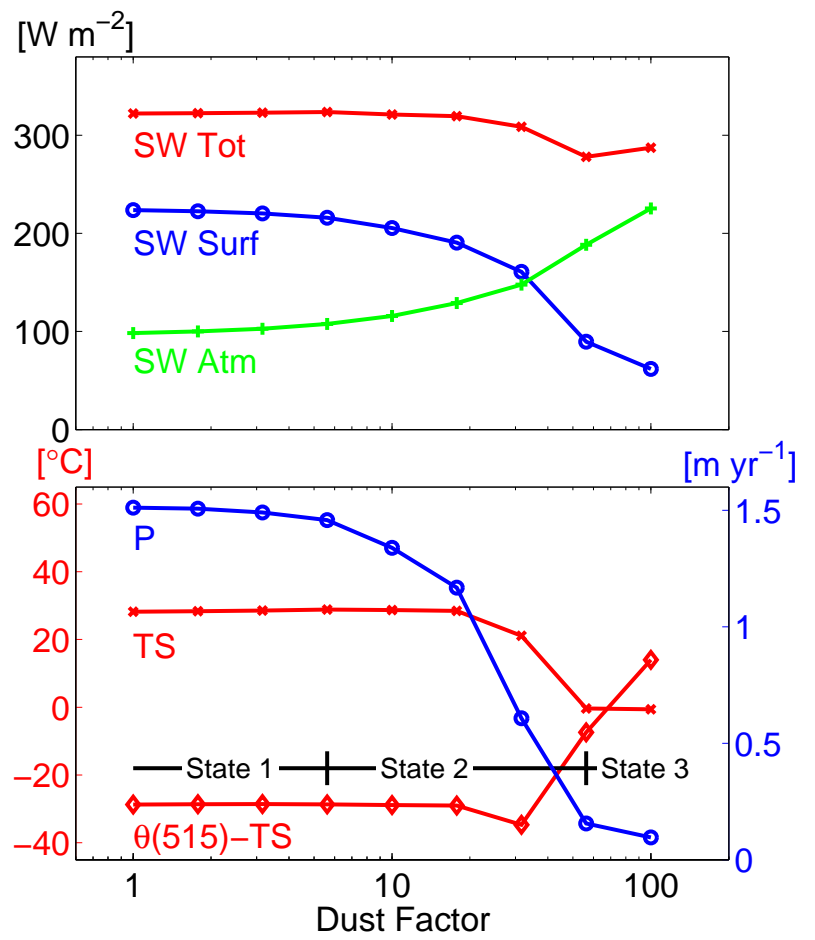

Fig. 1. Regimes in tropical stability and precipitation determined by atmospheric dust level. (top) The absorption of solar radiation by the surface (SW Surf), the atmosphere (SW Atm), and the sum of the surface and atmosphere (SW Tot) as a function of the factor by which current tropical dust levels are increased (dust factor). (bottom) The precipitation $(P)$, tropical surface temperature (TS), and the difference between mid-tropospheric $(515 \mathrm{mb})$ potential temperature and surface temperature $(\theta(515)-\mathrm{TS})$ as a function of the dust factor. In State 1 convection maintains the marginal convective stability of the troposphere. In State 2 absorption of solar energy by midtropospheric dust partially replaces convection in maintaining marginal convective stability. In State 3 solar absorption by dust causes an inversion.

the Earth. We now examine the influence of dust on glacial climate variability.

Calculations with a radiative-convective model (SCAM, see Appendix A for a model description) show that both reflection and absorption by atmospheric dust reduce radiation reaching the surface (Fig. 1), which in turn exerts a strong influence on global precipitation rate (Fig. 1), primarily, for small dust load, by reducing the energy available to evaporate water. A more subtle influence of shortwave radiation absorption on precipitation becomes important when the dust is increased to 5-20 times modern levels (State 2).

At these dust levels, absorption of radiation by dust begins to replace deep moist convection in maintaining the statistical equilibrium state of marginal convective stability in the upper troposphere. This would stabilize the high dust state by eliminating precipitation scavenging by both the deep convective cells and associated stratiform precipitation which, in the tropics, is sourced from the convective moisture (Houze, 
1997). This scavenging by wet deposition is the primary process by which fine aerosol is removed from the upper troposphere. We can obtain the reduction in precipitation scavenging in the upper troposphere because it is directly related to the shortwave radiation absorption induced decrease in deep convection, which is calculated by SCAM. Moreover, in the topics this relation between absorption of shortwave radiation by fine aerosol and the associated decrease in deep convection is close because it results from the fundamental requirement of convective statistical equilibrium (Emanuel, 1994). As an example, when atmospheric column dust loading is increased to ten times modern levels, deep convective precipitation in the upper troposphere is reduced by a factor of 2-3. Assuming a similar reduction in the net fine aerosol sink, which is dominated by wet deposition, implies that dust input to the atmosphere would only need to be increased by a factor of 2-8 for the upper tropospheric column dust concentrations to reach 5-20 times modern levels, at which point this state would persist. This increase in atmospheric dust input is well within the range of estimated dust source increase seen in the proxy record during cold Pleistocene periods (Thompson et al., 1989; Lambert et al., 2008; Fuhrer et al., 1999). If the dust is further increased to $\sim 30$ times modern, an inversion develops (State 3, Fig. 1). In this state deep convection shuts off completely and deep convective precipitation is reduced by more than an order of magnitude (Fig. 1).

We believe that the state in which the role of moist convection in maintaining marginal convective stability of the upper troposphere is partially assumed by absorption of radiation by dust (State 2) is a model for the large-scale behavior of the atmosphere during cold, dry, stadial climates. Switch-like transitions between the warm, wet, less dusty interstadial climate (State 1) and the cold, dry, dusty stadial climate (State 2) occur when the fine dust in the upper troposphere increases to values for which deep convection becomes substantially suppressed by the radiative influence of the dust, which occurs around dust factor 10 in Fig. 1. Producing the increase in upper tropospheric dust required to cross this precipitation control threshold depends on establishing widespread drought and the subsequent occurrence of severe wind events, which is a relatively rare coincidence of weather extremes. The limited extent of drying and cooling that occurred in the stadials suggests that, with the present configuration of potential dust source regions, full activation of available source regions arrests the destabilization in region 2 . The stochastic nature of the triggering events and the feedback stabilized cold/dry/dusty and warm/wet/less-dusty states is consistent with a two stable state system with memoryless process transitions as seen in the glacial climate record. Consistent with these statistical properties, the glacial climate can be phenomenologically modeled using a Langevin equation with a pseudo-potential having two minima representing the two stable states forced by noise representing the weather events (Ditlevsen, 1999).
With suitable parameter choice, a stochastic model of this kind produces a time series of dust concentration in good agreement with the ice core record. The contribution of our theory to this Langevin model is to provide a physical identification of the model noise with extreme weather events and of the two phenomenological stable equilibrium states of the pseudo-potential with the feedback stabilized cold/dry/dusty and warm/wet/less-dusty states. As an illustrative example, using a state variable of $x=\log _{10}$ (dust), we choose the interstadial state to correspond to the present dust level $(x=0)$ and a typical stadial dust level of 10 times the present dust level $(x=1)$. We then choose a potential $(U)$ corresponding to these equilibria, with a switch between them at $x=0.5$ (Fig. 2a). The corresponding Langevin equation is

$\dot{x}=-\frac{\mathrm{d} U}{\mathrm{~d} x}+\sigma \xi$,

with $\sigma=.1$ and $\xi$ Gaussian distributed white noise with zero mean and unit variance. This model produces a time series (Fig. 2c) of abrupt switches between the stable states with exponentially distributed waiting time indicative of a stochastic Poissson process, consistent with the glacial records. Additional information on the noise process involved can be obtained from the ice core data and these results indicate an $\alpha$ stable noise distribution consistent with that of hydrological extremes (Ditlevsen, 1999).

\section{Observables}

The theory advanced here predicts observables including a globally distributed increase in dust flux (Winckler et al., 2008; Lambert et al., 2008; Steffensen et al., 2008), drying as evidenced by widespread loess deposits (Sun et al., 2006) and xerification (Guthrie, 2001). In addition, reduction in precipitation scavenging in the upper troposphere during stadials is predicted to result in changes in atmospheric chemistry such as an increase in sulfate aerosol accumulation, which would provide a positive feedback stabilizing the stadial state. Increase in sulfate during glacials has been observed in Antarctic ice core data (Iizuka et al., 2012) and this increase in sulfate during glacials alone is predicted to potentially result in global cooling of order $2{ }^{\circ} \mathrm{C}$ (Iizuka et al., 2012; Tsai et al., 2010).

\section{Discussion}

The modeling approach we have pursued is sufficient to demonstrate the dust-destabilization feedback mechanism and establish its plausibility. The fact that similar behavior has not yet been simulated in the parameter regime currently being investigated with more complex models (Mahowald et al., 2006) does not rule out this mechanism given uncertainties in modeling the dust cycle. For example, the last 
(a) Pseudo-potential

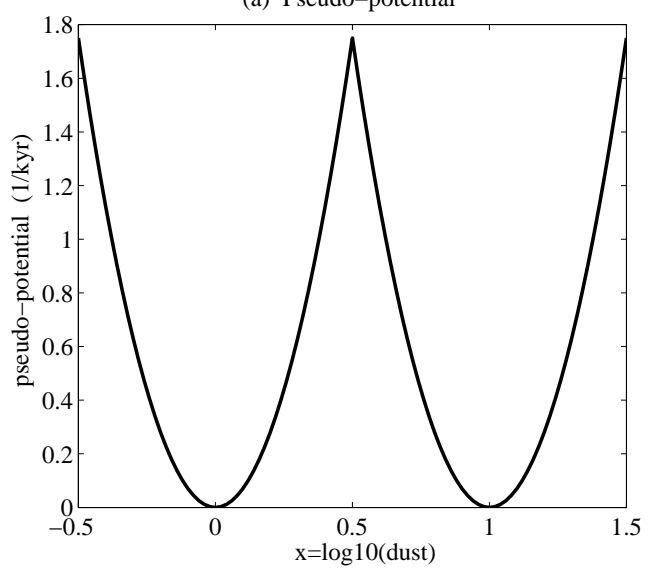

(b) Probability density function

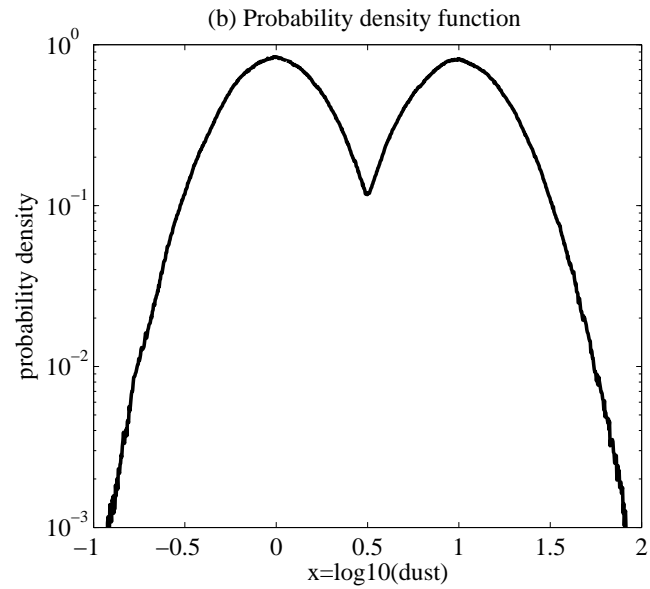

(c) Time series

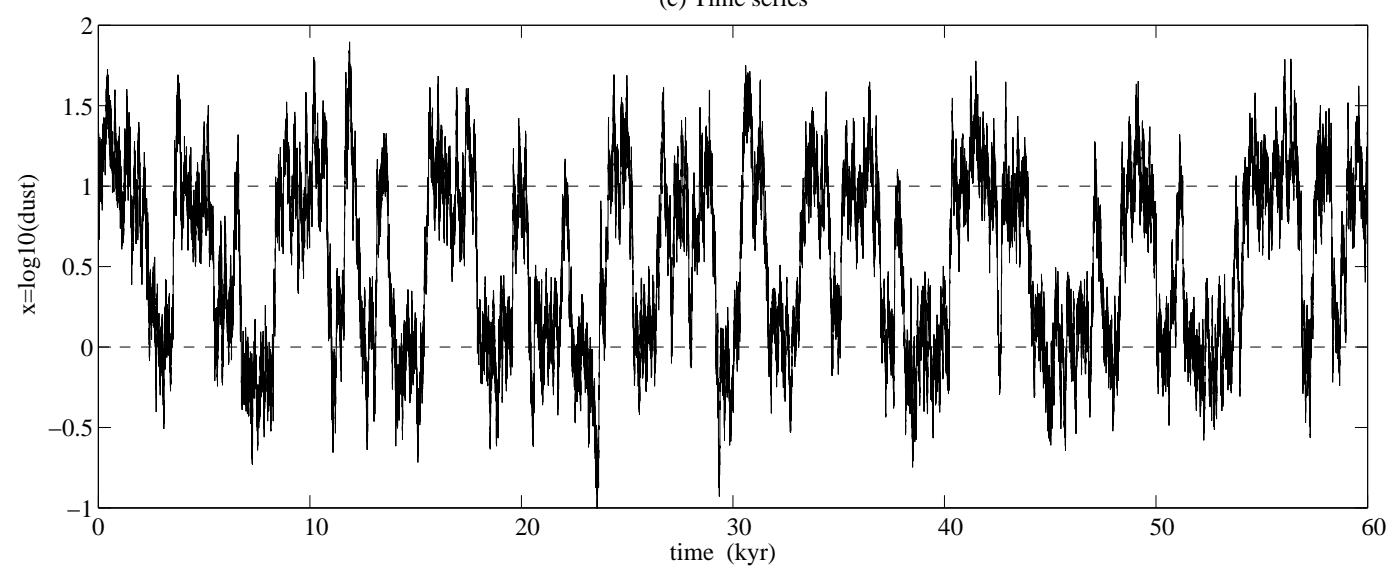

Fig. 2. Langevin Model of Dust Transitions. (a) Pseudo-potential corresponding to the stadial and interstadial equilibria and to the switch between them at $x=0.5$, where $x=\log _{10}$ (dust). (b) Probability of occurrence of states. (c) Time series of transitions between states with waiting time between transitions of $1600 \mathrm{yr}$.

glacial maximum dust flux estimates from specific glaciogenic sources made by Mahowald et al. (2006) vary by one to three orders of magnitude as a result of tuning uncertain source parameters. Additionally, dust optical properties are strongly affected by uncertain mineralogical parameters, such as hematite content (Sokolik and Toon, 1999), so that our qualitative estimate of 5-20 times increased dust load to establish the colder/dustier state 2 may represent an overestimate of the required dust load depending on the dust composition.

The SCAM model assumes aerosols interact primarily with shortwave radiation. This is appropriate for small aerosols, but large aerosols have substantial longwave crosssection that would tend to oppose the upper level heating and surface cooling effect of the small aerosols involved in the dust feedback destabilization. It is reasonable to neglect the longwave effects of large aerosols in this study because large aerosols are concentrated primarily in the vicinity of source regions and it is the small $\left(D_{\mathrm{d}}<2 \mu \mathrm{m}\right)$ aerosols that have long lifetimes, interact primarily with shortwave radiation, and produce strongly negative radiative forcing (Kok, 2011). We are proposing that a hemispheric to global scale upper atmosphere layer of these fine aerosol particles was established and stabilized by feedbacks arising from the small aerosols' suppression of precipitation which both decreased scavenging of aerosols and increased aridity in dust source regions.

Moreover, atmospheric dust load is a strong function of surface drying, which in turn is related to the particular sequence of global weather events. Even with identical boundary conditions, individual realizations of global weather events result in large integrated dispersion in continental scale drying on decadal and shorter time scales, as seen among realizations in ensemble AGCM simulations (Schubert et al., 2004). In addition, dust lofting is a strong nonlinear function of surface wind speed (Andersen et al., 1998) which also varies among ensemble members in simulations both with and without boundary condition influences. The effect of changes in atmospheric boundary conditions, 
such as are associated with ENSO and the PDO in a coupled AOGCM, is to produce an additional stochastic variation in regional weather patterns that serves to enhance the variance of the stochastic process inducing the dust state transition. Explicit simulation of the dust state transition is not possible in the present generation of climate models since dust lofting depends crucially on small space and time scale meso and micro scale processes (Schepanski et al., 2009) that are not resolved. It follows that the calculations presented here, while indicative, cannot establish precisely a sequence of events that would cause such a transition. The important concept is that a dust transition depending on a sequence of weather events would naturally satisfy the severe constraints that the transition mechanism be abrupt, bimodal, memoryless, noise-induced and not associated with a bifurcation.

We have chosen to put the stadial equilibrium in Fig. 2 at 10 times present dust in agreement with observations of dust, temperature and precipitation in glacial climates (Fig. 1). We believe the far dustier and colder equilibrium indicated by the relationship between dust and precipitation as state 3 in Fig. 1 may not be accessible because dust levels cannot increase further once all potential dust source regions have been fully activated. This observation suggests that the progressive increase in the severity of stadials during the Pleistocene culminating in the particularly severe LGM interval may be related to increased availability and activation of dust source regions. Over long time scales the distribution and activation of dust source regions is clearly also related to seasonal distribution of insolation and to variations in orography.

Many Antarctic climate records show evidence for a "bipolar seesaw" signature of abrupt climate change in which the millennial time scale temperature record is antiphased between the Greenland and Antarctic ice records (e.g., Blunier and Brook, 2001). This observation is in agreement with the role of the North Atlantic THC in producing global teleconnections and as an important component of the sequence of events associated with abrupt climate change. However, the exact order of events in the sequence which begins with the instigation of an abrupt climate change event has yet to be determined. Rapid reorganization of the hydrological cycle would clearly influence the stability of North Atlantic surface water to convection with a consequent effect on THC regime stability. Conversely, reduction in the THC resulting from non-meteoric fresh water input could produce an increase in dust through, for example, its teleconnection with the Asian monsoon. Testing these predictions would provide an interesting challenge for climate models.

\section{Conclusions}

Evidence preserved in Greenland ice cores and widespread tropical and mid-latitude ice and cave deposits reveals that glacial climates were characterized by abrupt, hemispheric to global scale transitions involving both temperature and the hydrological cycle. Greenland ice core records of these transitions imply an underlying mechanism that is bimodal, noise-induced, memoryless, and not associated with the variance increase and critical slowing indicative of approach to a bifurcation point. These characteristics severely constrain mechanisms of glacial abrupt climate variability. In this work we propose a mechanism for abrupt climate change that is consistent with these constraints from the record of rapid climate transitions. This mechanism is based on a precipitation/dust feedback in which weather events provide the noise that instigates transition between a stable cold/dry/dusty state and a warm/wet/less-dusty state.

\section{Appendix A}

\section{Model description}

In order to model the mechanism of dust-induced destabilization of glacial climates we use NCAR's single column atmospheric model (SCAM) (Hack et al., 2004). This model contains all aerosol, cloud, convection, and radiation representations of CAM (Collins et al., 2004; McCaa et al., 2004), NCAR's atmospheric general circulation model. We couple the model atmosphere to a mixed layer ocean with a depth of $50 \mathrm{~m}$, so that the equilibrated model conserves energy, which is important for determining precipitation. We apply an ocean heat flux divergence of $-70 \mathrm{~W} \mathrm{~m}^{-2}$ to this slab ocean to represent heat transport to higher latitudes. We apply dust to the model by multiplying the tropical-average of the seasonally-varying standard CAM aerosol dust climatology by a "dust factor" at each model level for each of the CAM dust size bins, which represent dust particles with diameter $0.1-1.0 \mu \mathrm{m}, 1.0-2.5 \mu \mathrm{m}, 2.5-5.0 \mu \mathrm{m}$, and 5.0$10.0 \mu \mathrm{m}$. Each dust bin has characteristic optical properties. We use a sea salt aerosol profile taken from the tropical Pacific and set all other aerosols to zero. Collins et al. (2004) contains a detailed description of the model's aerosol scheme. We apply a surface wind speed of $8 \mathrm{~m} \mathrm{~s}^{-1}$ to the model. We find similar results with surface wind speeds of 4 and $12 \mathrm{~m} \mathrm{~s}^{-1}$. We average model results over $20 \mathrm{yr}$ of converged solutions. We use a time step of $1200 \mathrm{~s}$; our results are very similar when we reduce the time step to $600 \mathrm{~s}$.

Acknowledgements. We thank N. Heavans, P. Ditlevsen, two anonymous reviewers, and M.-F. Loutre (the editor) for their comments and help improving this paper. This work was supported by NSF ATM-0902844, NSF ATM-0754332, NSF ATM-0123389 and NSF AGS-1246929.

Edited by: M.-F. Loutre 


\section{References}

Alley, R., D. Meese, C. Shuman, A. Gow, and K. Taylor: Abrupt increase in Greenland snow accumulation at the end of the Younger Dryas event, Nature, 362, 527-529, 1993.

Andersen, K., Armengaud, A., and Genthon, C.: Atmospheric dust under glacial and interglacial conditions, Geophys. Res. Lett., 25, 2281-2284, 1998.

Blunier, T. and Brook, E. J.: Timing of millennial-scale climate change in Antarctica and Greenland during the last glacial period, Science, 291, 109-112, 2001.

Chappellaz, J., Bluniert, T., Raynaud, D., and Barnola, J.: Synchronous changes in atmospheric $\mathrm{CH}_{4}$ and Greenland climate between 40 and 8 kyr BP, Nature, 366, 443-445, 1993.

Clement, A. and Peterson, L.: Mechanisms of abrupt climate change of the last glacial period, Rev. Geophys., 46, RG4002, doi:10.1029/2006RG000204, 2008.

Collins, W. D., Rasch, P. J., Boville, B. A., Hack, J. J., McCaa, J. R., Williamson, D. L., Kiehl, J. T., Briegleb, B., Bitz, C., Lin, S. J., Zhang, M., and Dai, Y.: Description of the NCAR Community Atmosphere Model (CAM 3.0), NCAR Technical Note, NCAR/TN-464+STR, Boulder, Colorado, 214 pp., 2004.

Ditlevsen, P.: Observation of $\alpha$-stable noise induced millennial climate changes from an ice core record, Geophys. Res. Lett., 26, 1441-1444, 1999.

Ditlevsen, P.: Climate transitions on long timescales, Contemp. Phys., 50, 511-532, 2009.

Ditlevsen, P. and Johnsen, S.: Tipping points: early warning and wishful thinking, Geophys. Res. Lett., 37, L19703, doi:10.1029/2010GL044486, 2010.

Dykoski, C., Edwards, R., Cheng, H., Yuan, D., and Cai, Y.: A highresolution, absolute-dated Holocene and deglacial Asian monsoon record from Dongge Cave, China, Earth Planet. Sc. Lett., 233, 71-86, 2005.

Emanuel, K.: Atmospheric Convection, Oxford University Press, New York 1994.

Farrell, B. F. and Ioannou, P. J.: Structural stability of turbulent jets, J. Atmos. Sci., 60, 2101-2118, 2003.

Fernández, W.: Martian dust storms: a review, Earth Moon Planets, 77, 19-46, 1997.

Fleitmann, D., Burns, S., Mudelsee, M., and Neff, U.: Holocene forcing of the Indian monsoon recorded in a stalagmite from Southern Oman, Science, 300, 1367-1369, 2003.

Fuhrer, K., Wolff, E., and Johnsen, S.: Timescales for dust variability in the Greenland Ice Core Project (GRIP) ice core in the last 100000 years, J. Geophys. Res.-Atmos., 104, 31043-31052, 1999.

Gildor, H. and Tziperman, E.: Sea-ice switches and abrupt climate change, Philos. T. Roy. Soc. A, 361, 1935-1944, 2003.

Guthrie, R. D.: Origin and causes of the mammoth steppe: a story of cloud cover, woolly mammal tooth pits, buckles, and inside-out Beringia, Quaternary Sci. Rev., 20, 549-574, 2001.

Hack, J. J., Truesdale, J. E., Pedretti, J. A., and Petch J. C.: SCAM Users Guide, available at: http://www.ccsm.ucar.edu/ models/atm-cam/docs/scam/ (last access: 1 January 2009), 2004.

Houze, R. A.: Stratiform precipitation in regions of convection: A meteorological paradox?, Bull. Am. Meteorol. Soc., 78, 21792196, 1997.

Iizuka, Y., Uemura, R., Motoyama, H., Suzuki, T., Miyake, T., Hirabayashi, M., and Hondoh, T.: Sulphate-climate coupling over the past 300,000 years in inland Antarctica, Nature, 490, 81-84, 2012.

Kok., J. F.: A scaling theory for the size distribution of emitted dust aerosols suggests climate models underestimate the size of the global dust cycle, Proc. Natl. Acad. Sci., 108, 1016-1021, 2011.

Lambert, F., Delmonte, B., Petit, J., and Bigler, M.: Dust-climate couplings over the past 800000 years from the EPICA Dome C ice core, Nature, 452, 616-619, 2008.

Mahowald, N. M., Muhs, D. R., Levis, S., Rasch, P. J., Yoshioka, M., Zender, C. S., and Luo, C.: Change in atmospheric mineral aerosols in response to climate: Last Glacial period, preindustrial, modern, and doubled carbon dioxide climates, J. Geophys. Res.-Atmos., 111, D10202, doi:10.1029/2005JD006653, 2006.

Mayewski, P., Meeker, L., Whitlow, S., Twickler, M., Morrison, M., Alley, R., Bloomfield, P., and Taylor, K.: The atmosphere during the Younger Dryas, Science, 261, 195-197, 1993.

McCaa, J., Rothstein, M., Eaton, B., Rosinski, J., Kluzek, E., and Vertenstein, M.: User's Guide to the NCAR Community Atmosphere Model (CAM 3.0), available at: http://www.ccsm. ucar.edu/models/atm-cam/docs/usersguide/ (last access: 1 January 2009), 2004.

McManus, J. F., Francois, R., Gherardi, J.-M., Keigwin, L. D., and Brown-Leger, S.: Collapse and rapid resumption of Atlantic meridional circulation linked to deglacial climate changes, Nature, 428, 834-837, 2004.

Rohling, E., Mayewski, P., and Challenor P.: On the timing and mechanism of millennial-scale climate variability during the last glacial cycle, Clim. Dynam., 20, 257-267, 2003.

Ruth, U., Bigler, M., Rothlisberger, R., Siggaard-Andersen, M.-L., Kipfstuhl, S., Goto-Azuma, K., Hansson, M. E., Johnsen, S. J., Lu, H., and Steffensen, J. P.: Ice core evidence for a very tight link between North Atlantic and east Asian glacial climate, Geophys. Res. Lett., 34, L03706, doi:10.1029/2006GL027876, 2007.

Schepanski, K., Tegen, I., Todd, M. C., Heinold, B., Bönisch, G., Laurent, B., and Macke, A.: Meteorological processes forcing saharan dust emission inferred from MSG-SEVIRI observations of subdaily dust source activation and numerical models, J. Geophys. Res., 114, 1-18, 2009.

Schubert, S., Suarez, M., Pegion, P., Koster, R., and Bacmeister, J.: On the cause of the 1930s dust bowl, Science, 303, 1855-1859, 2004.

Seager, R. and Battisti, D. S.: in: The Global Circulation of the Atmosphere, edited by: Schneider, T. and Sobel, A. H., Princeton University Press, Princeton, NJ, 331-377, 2007.

Sokolik, I. N. and Toon, O. B.: Incorporation of mineralogical composition into models of the radiative properties of mineral aerosol from UV to IR wavelengths, J. Geophys. Res., 104, 942-9444, 1999.

Steffensen, J., Andersen, K., Bigler, M., Clausen, H., Dahl-Jensen, D., Fischer, H., Goto-Azuma, K., Hansson, M., Johnsen, S., and Jouzel, J.: High-resolution Greenland ice core data show abrupt climate change happens in few years, Science, 321, 680-684, 2008.

Sun, Y., Chen, J., Clemens, S. C., Liu, Q., Ji, J., and Tada, R. T.: East Asian monsoon variability over the last seven glacial cycles recorded by a loess sequence from the Northwestern Chinese Loess Plateau, Geochem. Geophy. Geosy., 7, 1-16, 2006.

Thompson, L., Mosley-Thompson, E., Davis, M., Bolzan, J., Dai, J., Klein, L. K., Yao, T., Wu, X., Xie, Z., and Gundestrup, 
N.: Holocene-late Pleistocene climatic ice core records from Qinghai-Tibetan Plateau, Science, 246, 474-477, 1989.

Tsai, I.-C., Chen, J.-P., Lin, P.-Y., Wang, W.-C., and Isaksen, I. S. A.: Sulfur cycle and sulfate radiative forcing simulated from a coupled global climate-chemistry model, Atmos. Chem. Phys., 10, 3693-3709, doi:10.5194/acp-10-3693-2010, 2010.

Wang, Y., Cheng, H., Edwards, R., An, Z., and Wu, J.: A highresolution absolute-dated late Pleistocene monsoon record from Hulu Cave, China, Science, 294, 2345-2348, 2001.

Weaver, A., Sarachik, E., and Marotze, J.: Freshwater flux forcing of decadal and interdecadal oceanic variability, Nature, 353, 836838, 1991.
Winckler, G., Anderson, R., Fleisher, M., and McGee, D.: Covariant glacial-interglacial dust fluxes in the equatorial Pacific and Antarctica, Science, 320, 93-96, 2008.

Yuan, D., Cheng, H., Edwards, R., Dykoski, C., and Kelly, M.: Timing, duration, and transitions of the last interglacial Asian monsoon, Science, 304, 575-578, 2004.

Yung, Y., Lee, T., Wang, C., and Shieh, Y.: Dust: a diagnostic of the hydrologic cycle during the Last Glacial Maximum, Science, 271, 962-963, doi:10.1126/science.271.5251.962, 1996. 